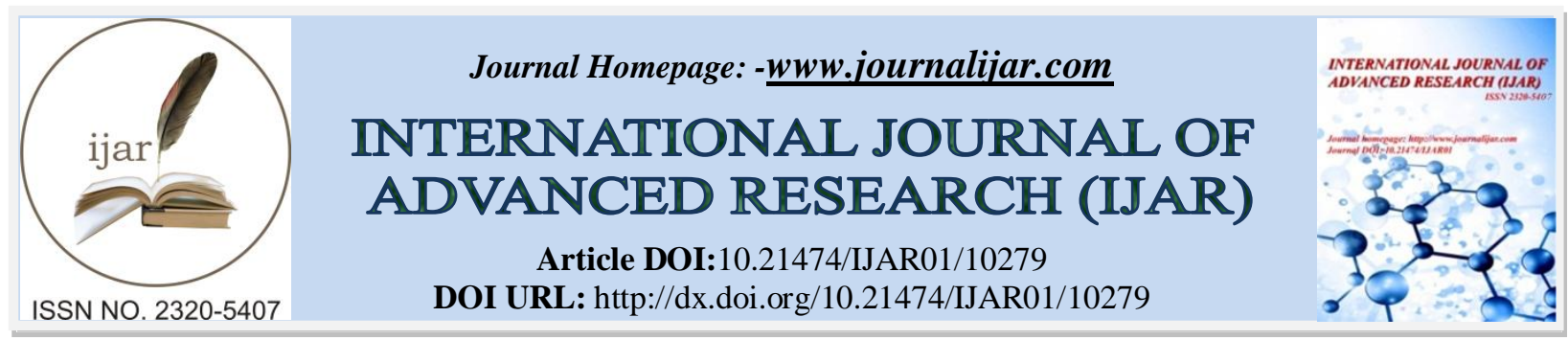

RESEARCH ARTICLE

\title{
SURFACE MORPHOLOGY AND OPTICAL PROPERTIES OF CUBIC-ZINC SULFIDE (c-ZnS) THIN FILMS
}

\section{Fransisco Kouadio Konan ${ }^{1,2}$ and Boko Aka ${ }^{1}$}

1. Laboratoire d'Energie Solaire et de Nanotechnologie (LESN) - IREN (Institut de Recherches sur les Energies Nouvelles), Université Nangui Abrogoua, 02 BP 801 Abidjan 02, Côte d'Ivoire.

2. ERDyS Laboratory, GMEEMDD Group, FSTM, Hassan II Casablanca University, B.P. 146, Mohammedia, Morocco.

\section{Manuscript Info}

\section{Manuscript History}

Received: 23 November 2019

Final Accepted: 25 December 2019

Published: January 2020

Key words:-

Dip-coating, c-ZnS, Morphology,

Transmittance
Abstract

Cubic zinc sulfide (c-ZnS) thin films have been prepared using dipcoating technique. X-ray diffraction pattern revealed cubic phase with the preferred (111) plane in $\mathrm{ZnS}$ films. Scanning electron microscope (SEM) analysis showed the granular shaped type of surface texture. The energy dispersive X-ray method indicated an excess of zinc. UVVisible spectroscopy is used to measure the transmittance of thin films which is found to be superior to $80 \%$. These experimental results showed that the as-grown $\mathrm{ZnS}$ nanoparticles were of high purity.

Copy Right, IJAR, 2020,. All rights reserved

\section{Introduction:-}

Zinc sulfide $(\mathrm{ZnS})$ is one of the promising II-VI semiconductor materials due to its valuable properties including catalytic, photoluminescence, electroluminescence properties (Choudapura et al., 2019; Lin and Ho, 2017). Recently, extensive studies (Pawar et al., 2017; Lin et al., 2013) have been carried out on the synthesis in ZnS nanosize crystalline structure in order to improve its properties for various applications such as ultraviolet light emitters, flat panel displays, spin functional devices, transparent conductive oxides, gas sensors and surface acoustic wave devices, photo-electrochemical energy conversion and photoconductors (Fang et al., 2011; Ates et al., 2007). It possesses different crystal structures i.e. cubic (c-ZnS: zinc blende) structure, having the lattice constant, $\mathrm{a}=5.409$ $\AA$ and optical band gap, $\mathrm{E}_{\mathrm{g}}=3.72 \mathrm{eV}$, and hexagonal ( $\mathrm{h}-\mathrm{ZnS}$ : wurtzite) structure, having the lattice constants $\mathrm{a}=\mathrm{b}=$ $3.812 \AA$ and $\mathrm{c}=6.26 \AA$ and $\mathrm{E}_{\mathrm{g}}=3.77 \mathrm{eV}$, both cubic zinc blende and hexagonal wurtzite and band gap energy, $\mathrm{E}_{\mathrm{g}}=$ $3.68 \mathrm{eV}$ (La Porta et al., 2014; Tiwary et al., 2014).

$\mathrm{ZnS}$ films have been synthesized through physical and chemical techniques including co-precipitation method (Choudapura et al., 2019), photo-assisted MOCVD (Yoon and Choi, 2013), RF mganetron sputtering (Abdallah et al., 2019), electrodeposition (Hennayaka and Lee, 2013), aerosol assisted chemical vapour deposition (Ehsan et al., 2013), chemical bath deposition (Padmavathy et al., 2018), chemical spray pyrolysis (Safeera et al., 2013), sol-gel (Turgut et al., 2012), pulsed laser deposition (Zhang et al., 2013), electron beam evaporation (Abdallah et al., 2019), etc. The physical way needs high reaction temperature, sophisticated equipment, whereas the chemical route is low priced technique, easy, and handy to perform. So, the sol-gel via dip-coating technique for preparing zinc sulfide nanoparticles has become very attractive due to its simplicity and ease of scale-up in laboratory.

From literature survey, dip-coating technique is defined as a coating process in which the cleaned substrate is dipped into a tank containing the coating solution and then withdrawn at a well-defined speed in order to obtain uniform

Corresponding Author:- Fransisco Kouadio Konan

Address:- Laboratoire d'Energie Solaire et de Nanotechnologie (LESN) - IREN (Institut de Recherches sur les Energies Nouvelles), Université Nangui Abrogoua, 02 BP 801 Abidjan 02, Côte d’Ivoire. 
film. It is used both, in industry coating process to manufacture bulk products in diverse fields, and in academic research to prepare thin film coatings.

In this research, we report the surface morphology and optical properties of cubic-zinc sulfide (c-ZnS) thin films with the chemical method via dip-coating technique. Organization of this research paper is done into four sections i.e. Introduction, Materials and Methods, Results with Discussion, and Conclusion. The introduction section is a brief review of literature elaborated on some works done by various researchers on $\mathrm{ZnS}$. Materials and methods section contains precursor's source and chemicals utilized for the synthesis of $\mathrm{ZnS}$ and characterization techniques. Results and Discussion section details on the characterization results, analysis and interpretation. Conclusion section provides the major results.

\section{Materials and Methods:-}

All analytical grade reagents were used as received without further purification. Film deposition was carried out by using commercially available glass slides as substrates which were initially cleaned and rinsed in acetone, double de-ionised water and finally ultrasonically cleaned.

Dip-coating method was employed to deposit $\mathrm{ZnS}$ thin films onto glass substrates using zinc nitrate (zinc ion source) and thiourea (sulfur ion source). To prepare the precursor solution, we use $0.25 \mathrm{M}$ zinc nitrate, $0.55 \mathrm{M}$ thiourea with isopropyl alcohol $80 \%$ and $20 \%$ de-ionsied water. The solution was stirred continuously for 2 hours at room temperature to obtain a clear homogenous solution. The stirred solution was taken place in a beaker and the cleaned glass substrates were dipped in the solution for three times at regular intervals at room temperature using a customized automatic dip-coating system.

The morphology investigation and compositional analysis of the nanoparticles have been carried out using scanning electron microscope (SEM) equipped with energy dispersive X-ray analyzer (EDX). X-Ray diffraction measurements were performed using Bruker D8 advance Diffractometer with $\mathrm{Cu}$-Ka radiation. Data were recorded across a $2 \theta$ range of 20 to $65^{\circ}$ with a step size of $0.05^{\circ}$. The optical transmittance (T) of the films have been recorded using UV-Vis spectrophotometer.

\section{Results and Discussion:-}

The morphology of the as-deposited thin film was studied by using SEM images. Figure 1a shows the SEM images of the $\mathrm{ZnS}$ nanoparticles. The uniform deposition with spherical grains in surface and granular shape morphology were observed. The prepared films were homogeneous, smooth, and adherent to the glass substrate. EDX spectra (Figure $1 \mathrm{~b}$ ) confirms the presence of expected elements zinc ( $\mathrm{Zn})$ and sulfur $(\mathrm{S})$ in the samples. Low peaks of $\mathrm{C}$, Si, $\mathrm{Ca}$ are also detected. These peaks come from the underlying substrate (glass) and the surrounding air atmosphere. Moreover, the existence of only zinc and sulfur peaks suggests the formation of pure and single structure of ZnS nanoparticles. The elemental composition analysis is shown in Figure 1d with an excess of zinc. Similar type of elemental analysis for zinc rich $\mathrm{ZnS}$ has also been reported by researchers (Abdallah et al., 2019).

Figure 1c presents the typical X-ray diffraction pattern of $\mathrm{ZnS}$ films. Three broad peaks corresponding to the (111), (220) and (311) lattice planes located at $2 \theta$ values of $28.59^{\circ}, 48.12^{\circ}$ and $56.48^{\circ}$ are detected which matched well with reported data (ICSD \# 01-080-0020) which can be assigned to the cubic phase of ZnS. As can be clearly seen, the diffraction peaks show the cubic structure with preferred orientation along (111) plane without any impurities or secondary phase. Such a XRD (111) plane was reported by researchers (Akhtar et al., 2015). 


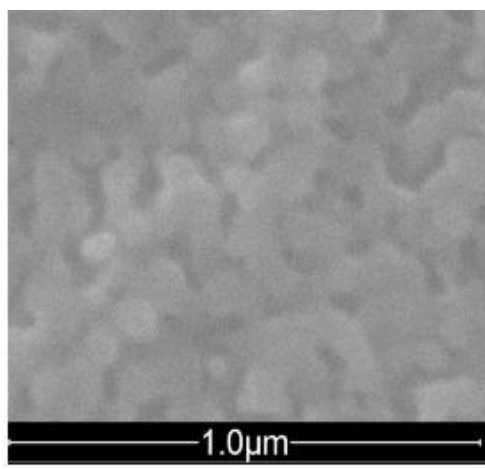

(a)

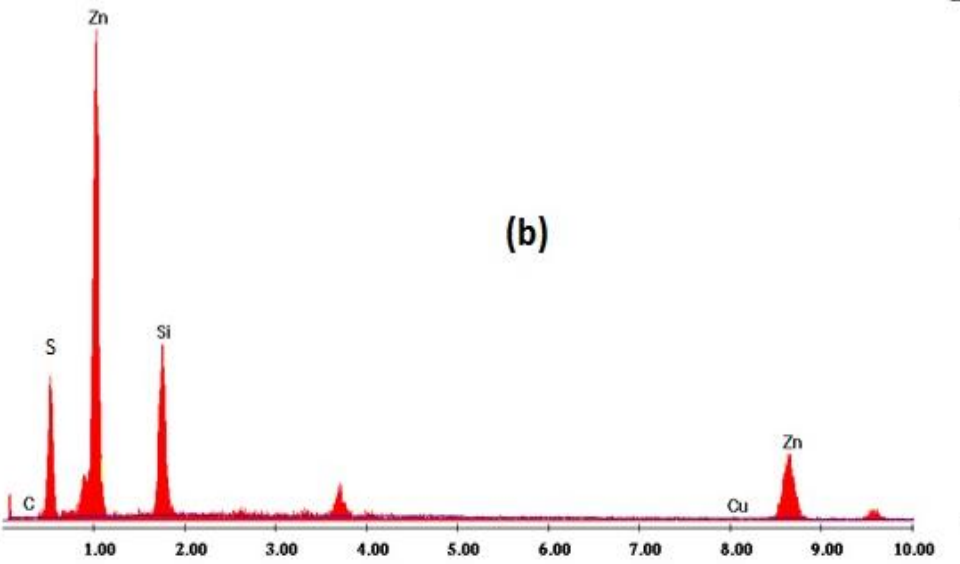

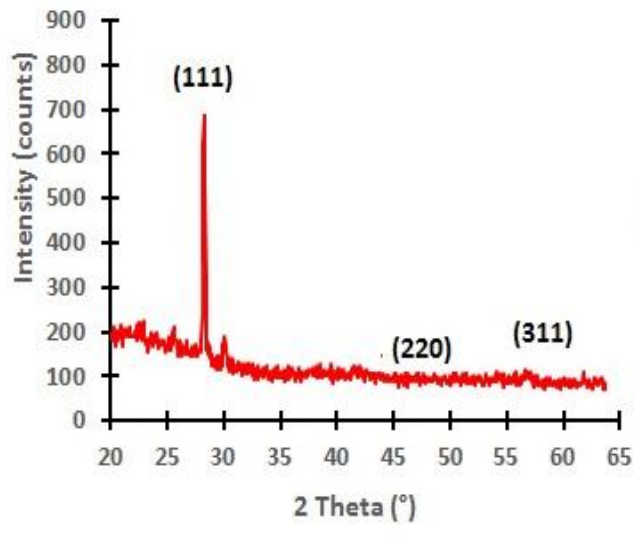

Element Series Weight \% Atomic \%

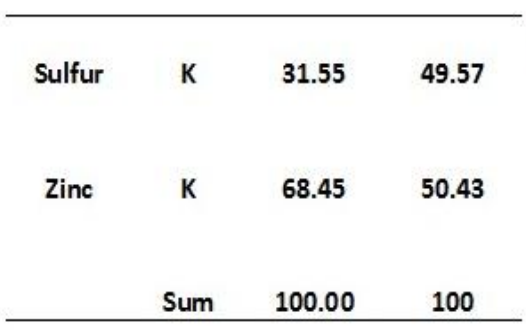

(d)

Figure 1: SEM image (a), EDX spectra (b), (c) X-ray diffractogramm and (d) elemental composition of a typical CBD-CdS film on glass.

Based on Figure 1c, films exhibit the highest intensity of X-ray diffraction peak on (111) plane, therefore the calculation of the average crystallite size was highlighted at (111) plane. Finally, the average crystallite size was evaluated using XRD data in accordance with thefamiliar Scherrer equation (Alexander and Klug, 1950; Guinier, 1963).

$\mathrm{D}=\frac{0.9 \lambda}{\beta \cos \theta}$

Where $\lambda(\lambda=1,5406 \AA)$ is the wavelength of the X-ray radiation used, $\theta$ is the Bragg diffraction angle of the XRD peak and $\beta$ is the broadening of the diffraction line at half maxima measured in radian.The average crystallite size estimated is $50.1 \mathrm{~nm}$.

Dislocation density $(\delta)$ and micro strain $(\varepsilon)$ of the $\mathrm{ZnS}$ nano-grains were calculated using the following equations (2) and (3) (Gherouel et al., 2012; Sahay and Nath, 2008; Klug and Alexander, 1974).

$\delta=\frac{1}{D^{2}}$

$\varepsilon=\frac{\beta \cos \theta}{4}$

The dislocation density $(\delta)$ and micro strain $(\varepsilon)$ of the $\mathrm{ZnS}$ nano-grains are found to be about $3.83 .10^{14} \mathrm{Lines}^{-\mathrm{m}^{-2}}$ and $28.10^{-4}$ respectively.

Further investigation from the diffractogramm can be obtained from analysis of the texture coefficient TC (hkl) which is the extent of preferred orientation, compared to other observations. The texture coefficient of a plane (hkl) is given by (Kumar et al., 2015). 


$$
T C_{(h k l)}=\frac{\frac{I_{(h k l)}}{I_{0}(h k l)}}{\frac{1}{N}\left(\sum_{i=1}^{N} \frac{I_{(h k l)}}{I_{0(h k l)}}\right)}
$$

Where $\mathrm{I}(\mathrm{hkl})$ is the measured relative intensity of each (hkl) peak, $\mathrm{I}_{0}(\mathrm{hkl})$ is the relative intensity of the corresponding plane, provided by the JCPDS-ICDD card and $\mathrm{N}$ is the number of reflections observed.TC(hkl) calculated values of $\mathrm{ZnS}$ thin films are tabulated in Table 1.

Table 1:- Values of texture coefficient TC (hkl).

\begin{tabular}{|c|c|c|c|}
\hline (hkl) plane & $(111)$ & $(220)$ & $(311)$ \\
\hline TC $(\mathrm{hkl})$ & 2.42 & 043 & 0.31 \\
\hline
\end{tabular}

Optical properties of $\mathrm{ZnS}$ thin films were performed by measuring transmittance in the range of wavelength 200$1000 \mathrm{~nm}$ by subtracting the glass substrate as a reference. The transmittance of the as-deposited films is presented in Figure 2. The optical transmission of the films varied from $60 \%$ to $90 \%$ in the region of visible wavelength.

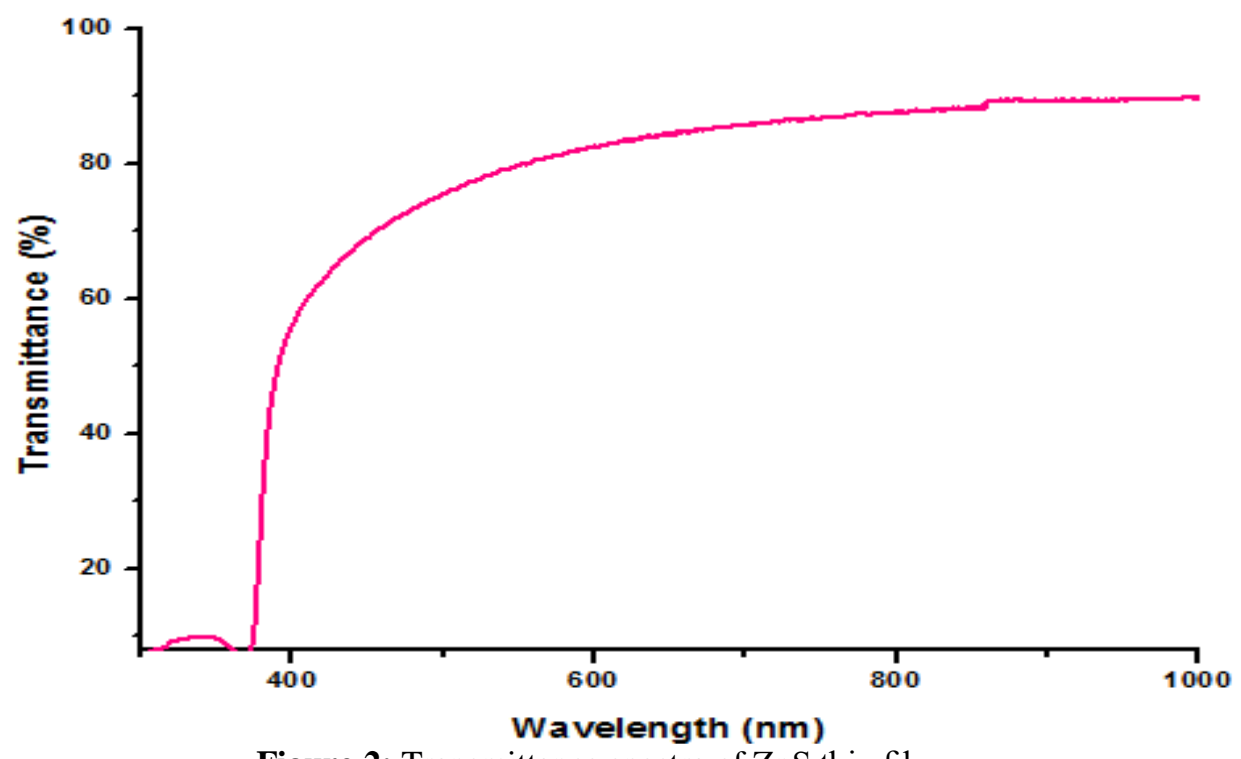

Figure 2: Transmittance spectra of $\mathrm{ZnS}$ thin films.

\section{Conclusion:-}

Cubic zinc sulphide (c-ZnS) thin films were obtained onto glass substrate by dip-coating route at room temperature. The diffraction peaks show the cubic structure with preferred orientation along (111) plane without any impurities or secondary phase. The formed $\mathrm{ZnS}$ films were characterized by an excess of zinc and uniform distribution of the chemical composition over the film surface. The films had good adhesion to the substrate surface and exhibit high transmittance (60 -90\%). The smorphological and optical properties of films have been improved.

\section{Acknowledgements:-}

The authors are indebted tothank the anonymous reviewers for the instruction.

\section{References:-}

1. Abdallah, B., Alnama, K. and Nasrallah, F. (2019): Deposition of ZnS thin films by electron beam evaporation technique, effect of thickness on the crystallographic and optical properties. Modern Physics Letters B, 1950034. doi:10.1142/s0217984919500349 
2. Abdallah, B., Zidan, M.D. and Allahham, A. (2019): Deposition of ZnS films by RF magnetron sputtering: Structural and optical properties using Z-scan technique. International Journal of Modern Physics B, 33(29); 1950348-1950357.

3. Akhtar, M.S., Malik, M.A., Riaz, S., Naseem, S. and O'Brien, P. (2015): Optimising conditions for the growth of nanocrystalline ZnS thin films from acidic chemical baths.Mater. Sci. Semicond. Process., 30; 292-297.

4. Alexander, L. and Klug, H.P. (1950): Determination of Crystallite Size with the X-Ray Spectrometer. Journal of Applied Physics, 21(2); 137-142.

5. Ates, A., Yıldırım, M.A., Kundak, M. and Astam, A. (2007): Annealing and light effect on optical and electrical properties of ZnS thin films grown with the SILAR method. Mater. Sci. Semicond. Process., 10; 281-286.

6. Choudapura, V.H., Kapatkara, S.B. and Rajub, A.B. (2019): Structural and optoelectronic properties of zinc sulfide thin films synthesized by co-precipitation method. ACTA CHEMICA IASI, 27(2); 287-302.

7. Davar, F., Mohammadikish, M., Loghman-Estarki, M.R. and Hamidic, Z. (2012): Synthesis of Spherical ZnS Based Nanocrystals Using Thioglycolic Assisted Hydrothermal Method. CrystEngComm, 14; 7338-7344.

8. Ehsan, M.A., Peiris, T.A.N., Wijayantha, K.G.U., Khaledi, H., Ming, H.N., Misran, M., Arifin, Z. and Mazhar, M. (2013): Surface morphological and photoelectrochemical studies of $\mathrm{ZnS}$ thin films developed from single source precursors by aerosol assisted chemical vapour deposition. Thin Solid Films, 540; 1-9.

9. Fang, X., Bando, Y., Gautam, U.K., Zhai, T., Zeng, H., Xu, X., Liao, M. and Golberg, D. (2009): ZnO and ZnS Nanostructures: Ultraviolet-Light Emitters, Lasers and Sensors. Crit. Rev. Solid State Sci., 34; 190-223.

10. Fang, X., Zhai, T., Gautam, U.K., Li, L., Wu, L., Bando, Y. and Golberg, D. (2011): ZnS nanostructures: From synthesis to applications. Prog. Mater. Sci., 56; 175-287.

11. Gherouel, D., Gaied, I., Boubaker, K., Yacoubi, N. and Amlouk, M. (2012): Some physical investigations of $\mathrm{AgInS}_{2-\mathrm{x}} \mathrm{Se}_{\mathrm{x}}$ thin film compounds obtained from $\mathrm{AgInS}_{2}$ annealed in seleneide atmosphere. Journal of Alloys and Compounds, 545; 190-199.

12. Guinier. (1963): X-Ray diffraction, Freeman. San Francisco, CA: USA; 186-209.

13. Hennayaka, H.M.M.N. and Lee, H.S. (2013): Structural and optical properties of ZnS thin film grown by pulsed electrodeposition. Thin Solid Films, 548; 86-90.

14. Klug, H.P. and Alexander, L.E. (1974): X-Ray Diffraction Procedures for Polycrystalline and Amorphous Materials, Wiley, NewYork.

15. Kumar, M., Kumar, A. and Abhyankar, A.C. (2015). Influence of Texture Coefficient on Surface Morphology and Sensing Properties of W-Doped Nanocrystalline Tin Oxide Thin Films. ACS Applied Materials \& Interfaces, 7(6); 3571-3580.

16. La Porta, F.A., Andre, J., Li, M.S., Sambrano, J.R., Varela J.A. and Longo, E. (2014): Zinc blende versus wurtzite $\mathrm{ZnS}$ nanoparticles: control of the phase and optical properties by tetrabutylammonium hydroxide Phys. Chem. Chem. Phys., 16; 20127-20137.

17. Lin, M-H. and Ho, C-H. (2014): Synthesis and Optical Characterization of Oxygen-Incorporated $\mathrm{ZnS}_{(1-\mathrm{x})}$ monodispersed $\mathrm{Ni}^{2+}$ doped $\mathrm{ZnS}$ nanoparticles. Appl. Nanosci., 4; 67-75.

18. Lin, K.B. and Su, Y.H. (2013): Photoluminescence of Cu:ZnS, Ag:ZnS, and Au:ZnS Nanoparticles Applied in BioLED. Appl. Phys. B, 113; 351-359.

19. Padmavathy, V., Sankar, S. andPonnuswamy, V. (2018): Influence of thiourea on the synthesis and characterization of chemically deposited nano structured zinc sulphide thin films. Journal of Materials Science: Materials in Electronics, 29(9); 7739-7749.

20. Pawar, A.S, Mlowe, S, Garje S.S., Akerman M.P. and Revaprasadu N. (2017): Zinc thiosemicarbazone complexes: single source precursors for alkylamine capped $\mathrm{ZnS}$ nanoparticles. Inorg Chim Acta, 463:7-13.

21. Sahay, P.P. and Nath, R.K. (2008): Al-doped ZnO thin films as methanol sensors. Sens. Actuators, B, 2; 654-659.

22. Shamsipur, M., Rajabi, H.R. (2014): Pure zinc sulfide quantum dot as highly selective luminescent probe for determination of hazardous cyanide ion. Mater Sci Eng C, 36; 139-145.

23. Tiwary, C.S., Saha, S., Kumbhakar, P. and Chattopadhyay, K. (2014): Observation of Combined Effect of Temperature and Pressure on Cubic to Hexagonal Phase Transformation in $\mathrm{ZnS}$ at the Nanoscale. Cryst. Growth Des. $14 ; 4240-4246$.

24. Turgut, G., Fahri Keskenler, E., Aydın, S., Doğan, S., Duman, S., Sönmez, E., Esen, B. and Düzgün, B. (2013). A study on characterization of $\mathrm{Al} / \mathrm{ZnS} / \mathrm{p}-\mathrm{Si} / \mathrm{Al}$ heterojunction diode synthesized by sol-gel technique. Materials Letters, 102-103; 106-108.

25. Yoon, Y.G. and Choi, I.H. (2013): Preparation of ZnS thin films by using photoassisted MOCVD. Journal of the Korean Physical Society, 63(8); 1609-1614.

26. Zhang, W., Zeng, X., Lu, J. and Chen H. (2013): Phase controlled synthesis and optical properties of ZnS thin films by pulsed laser deposition. Materials Research Bulletin, 48(10): 3843-3846. 